\title{
THE RELATIONSHIP BETWEEN MOTIVATION COMPONENTS AND PREFERRED LEARNING COMPONENTS AMONG STUDENTS AT INTERNATIONAL UNIVERSITY OF SARAJEVO
}

\author{
Almasa Mulalić \\ International University of Sarajevo, Bosnia and Herzegovina \\ Nudžejma Obralić \\ International University of Sarajevo, Bosnia and Herzegovina
}

\begin{abstract}
ते

Motivation plays an important role in all forms of the success, especially in language learning. Motivation in English language learning often conditions the academic achievement of the students. This and similar predicaments led SLA researchers to develop different methodologies to determine the level of motivation among different types of students. Therefore, this paper aims to determine motivation components of English language learning; preferred learning components/methods; and the relationships between motivational components and preferred learning components/methods among IUS students. For testing the main research questions, Smidth's (2006) adopted questionnaire was distributed to 70 students at the International University of Sarajevo. The research findings indicated that extrinsic motivation $(\mathrm{M}=34.15)$ was the highest motivational factor for the students. Expectation as a motivational factor (M $=26.4)$ was at the second place for the students. Motivational strength with the $(M=13.00)$ followed as the next motivational factor. Intrinsic motivation $(\mathrm{M}=12.97)$, stereotypical attitudes toward Americans \& British $(\mathrm{M}=12.15)$, personal psychological needs $(\mathrm{M}=$ 9.06) with their means as shown in the brackets were the least influential factors in students motivation. We have also found the correlation between the Motivational Components and the Preferred Learning components.
\end{abstract}

Keywords: Motivation Components; Second Language Acquisition; Preferred Learning Components/Methods; Stereotypical Attitude; International University of Sarajevo

\section{Introduction}

Motivation represents the feelings of the learner towards the particular target language, its culture and the individual pragmatic reasons for learning a foreign language (Horwitz, 1990). According to Keller (1983) "motivation refers to the choices people make as to what experiences or goals they will approach or avoid and the degree of effort they will excerpt in this report" (p. 389). Tackling the motivation and language learning emerged out of the curiosity of the researchers to investigate and evaluate motivation in foreign language learning at International University of Sarajevo (IUS). Since learning foreign language is inherently difficult it would be of a great satisfaction if we, researchers, uncover problems and difficulties that foreign language learners face on their path in foreign language learning process at the International University of Sarajevo. Certainly, research results will reveal the problems and offer solutions that would help students overcome the obstacles that hinder their language learning.

Researchers identified different types of motivation that students have while learning the language. Gardner and Lambert (1972) addressed two types of motivation: integrative 
and instrumental. The integrative motivation encompasses learning the language with the intention of participating in the culture of its people. Integrative motivated learners want to learn the target language for better understanding the people who speak the language and mingle with the people from a new culture. Integrative motivation refers to "an openness to identify at least in part with another language community (Gardner and Masgoret, 2003, p. 126). Learners with an instrumental motivation learn a language because they have different reasons, such as getting a higher salary or acceptance into a college. Gardner and Lambert (1992) considered instrumental motivation as a means to get social and economic reward through L2 learning. In addition, instrumental motivation insinuates that a learner learns the language due to opportunities and chances in their future carriers and jobs. Since they have great impact on language learning, these two types of motivation can affect and direct the procedure and outcome of learning. Cook (2000) further believes that the integrative and instrumental motivation suggested by Gardner and Lambert is useful and effective factor for second language learning. In the further classification of the motivation researchers talk about extrinsic motivation due to some external rewards, while intrinsic motivation is the motivation that comes from within an act we perform. Woolfolk (1998) defines intrinsic motivation as, "motivation that stems from factors such as interest or curiosity“(p. 374). Santrock (2004) also argues that "extrinsic motivation involves doing something to obtain something else (a means to an end)" (p. 418).

Matching motivation in English language learning and learner's preferences with classroom activities is inevitable for an effective language acquisition. Learning second language, from students' perspective is sometimes different from the instructors' perspectives. There has been a lot of research on how to achieve the effective outcomes while learning second language. What are the common effects related to second language acquisitions? What are the most important core effects in the terms of students' learning success and ways of acquiring knowledge? What is the unique formula for effective teaching and learning? What students need while learning second language? Since there has been no enough investigation on what really affects students and the learning process while learning second language in the context of learning process, we decided to apply the investigation at the International University in Sarajevo in Bosnia and Herzegovina. It has been a dilemma about effective impacts of effective second language learning, thus, we have noticed that the particular components of motivation are precisely important for achieving positive outcomes.

Therefore, this study examines:

- motivational components of foreign language learning among IUS students;

- $\quad$ preferred learning components/methods among IUS students;

- the correlation between motivational components and preferred learning components/methods.

\section{Motivation and Foreign Language Learning}

The study of motivation has been a prominent area for research in psychology and education for many years (Dörnyei, 2001a). This interest may be related to a wide spread perception of classroom teachers who tend to regard student motivation as the most important factor in educational success in general (Dörnyei, 2001b). Regarding the literature on L2 motivation there are two main divisions. The first one is composed out of research based on Gardner's socio-educational model in which the role of integrative motivation (comprised of integrativeness, attitudes toward the learning situation, and 
motivation) was largely elaborated as a prerequisite of L2 attainment. The other stream is more interested in the implementation of a new proposed aims in L2 motivation (Crookes \& Schmidt, 1991). Crooks and Schmidt (1991) proposed a number of alternative models with an attempt to gain a more in-depth understanding of L2 learning motivation within mainstream education. The first branch in this kind of research investigates causal relationships among possible individual-difference variables with various L2 achievement measures. However, the second stream attempts to identify possible variables that could influence learners' motivations within the immediate L2 learning context. In this paper, researchers will review some of the most influential literature in L2 motivation.

Engin (2009) argued that instrumental motivation is based on a pragmatic approach whereas integrative motivation depends on personal willingness and desire to achieve certain goal in a life. Motivation plays a crucial role in willingness of students to obtain knowledge and capabilities to use L2 for variety of purposes. Moiinvaziri (2009) argued that English language learners were motivated instrumentally as well as integrativelly. This claim was in conflict with the researchers who claimed that only instrumental motivation is important in SLA. He concluded that in English Language learning, both instrumental \& integrative motivation are important. Then, Al-Hazemi (2000) argued that desire to learn English language should arise from within the learner. In an ideal situation, learners should have very high desire to learn foreign language. According to him, the strong desire for L2 learning contributes to a high degree of competence and success in language learning. Dornyei (1994) stated that the nature of social and pragmatic dimensions of target language depends on who, what and where i.e. who learns the language, what language and where.

Oller et. al. (1977) argued that motivation in L2 acquisition is very important. In their research they concluded that Chinese learner were integratively motivated while learning English while Mexican American were instrumentally motivation. According to their research, instrumental motivation is the best predictor of language proficiency in SLA. They also draw attention to the obvious difference between second language and foreign language contexts as well. Then, in the two subsequent studies of Japanese learners of EFL, the relationship between attitudes and attained proficiency in English was much weaker than with the ESL learners and was also less easily explained by existing theories. The weaker relationship, of course, was in accord with our hypothesis that the relationship ought to be somewhat weaker in a foreign language setting.

Researchers most often talk about anxiety as one of the factors that hinder second language acquisition. When we suspect anxiety among our students, we usually relate it to the trait with variation in the experience of the unpleasant emotional state associated with subjective feelings of tension, apprehension, and worry as well as activation or arousal of the autonomic nervous system. According to MacIntyre (1999) foreign language anxiety is "worry and negative emotional reaction aroused when learning or using a second language" (p. 27). Indeed, learning a foreign language is a stressful activity for many learners (Hewitt \& Stefenson, 2011). Therefore, many researchers have examined the role of anxiety in language learning since early 1970s (e.g. Phillips, 1992; Gardner, 2005). Their research has shown that there is a negative relationship between FL anxiety and the level of achievement.

One of the variables affecting second language acquisition and hinders language comprehension is the stereotypical attitudes toward Americans and British. There are many different opportunities in today's world for traveling and interaction with different 
people. This is because of the technological advances and globalization. There are many researchers coming from different ethnic backgrounds, and interacting with different people around themselves. When this happens, and when a person communicates with a person from different culture, they tend to see in that person a representative of the country or the community. This is called prejudice and is an unfair negative attitude toward a social group or a member of that group. According to Stangor (2001), prejudice is a negative attitude toward members of a group. Dörnyei (1990) underlines the limited scope of attitudes toward the native speaker community to explain learner behaviors in a foreign language setting when the target language is an international language.

Gardner (2002) argues that learners' attitudes toward foreign language speaker groups influence their motivation and proficiency (p. 64). Furthermore, according to the acculturation model for second language acquisition by Schumann (1978), attitude is an important social factor, which facilitates learning in a second language-learning context where learners and native speakers have positive attitudes toward each other. This type of attitude merely focuses on the native speaker group, which makes Gardner's typology restricted to second language contexts where learners and native speakers frequently encounter in formal and informal contexts. However, in foreign language contexts learners have fewer opportunities to interact with the members of the foreign language community.

Maslow (1962) proposed the most prominent model of personal psychological need. Maslow wanted to understand what motivates people to be successful. He proposed that people are equipped with a set of motivation system unrelated to rewards or unconscious desires. People's personal psychological needs will be met if they live in the environment that suits their personality, and when they engage in a proper behavior in relation to other people. Similarly so Decy and Rayan (2002) argue that people's satisfaction of their needs for autonomy depends on their experience in their social and cultural environment, especially when their bosses, teachers and/or parents listen to their opinions and are supportive of their choices. Research also shows that people's needs for autonomy and competence are better satisfied when they are engaged in behaviors that are intrinsically motivated.

\section{Research Methodology}

The study was carried out at the International University of Sarajevo, Bosnia and Herzegovina. IUS is the international and multicultural institution of higher learning, having the goal to educate new generations who will lead their countries towards sociopolitical, scientific and economic progress and prosperity. The University also represents a unique opportunity for the young people to get education from highly qualified and prominent professors and researchers.

The focus group was comprised of 70 students $(\mathrm{N}=70)$ attending ENG 111 Freshman English courses during Spring Semester, 2014/2015. This course aims to enhance student's academic writing skills, research skills, public speaking, and presentation skills. The first part of the course deals with scanning, skimming, clustering, prewriting, drafting, and revising techniques. Such techniques will be applied to various forms of writing and research. The second part of the course deals with academic research skills, whereby students will learn how to organize research papers and how to incorporate different types of materials and sources into writings. Public speaking strategies will be explored profoundly by involving student's in-class presentations. Students will be evaluated on 
their ability to construct sentences in grammatically correct manner and on their correct use of English vocabulary words.

The instrument used in this study was adapted from R. Schmidt, D. Boraie and Omneya Kassabgy who designed it to test the research questions and hypothesis stated in their research. The questionnaire was composed of 50 items, which implied motivation of students, and 22 items for the preferences and instructional activities, with a rating scale from one to five. The questionnaire consisted of background information questions and 72 questions to probe into students' attitudes (Schmidt, Richard, Boraie, Deena, \& Kassabgy, Omneya, 1996).

Before data collection, the students were asked for permission to participate in this research and they agreed to do it. The procedures for the distribution of the questionnaire took place during the usual classes and were completed by all the students attending the freshman courses. With the instrument, students at IUS identified preferences towards the motivational components such as:

1. extrinsic motivation;

2. expectations;

3. anxiety;

4. motivational strength;

5. intrinsic motivation;

6. stereotypical attitudes toward Americans \& British;

7. personal psychological needs.

Besides, the instrument also identified the components of learner preferences for specific classroom practices and activities:

1. Balanced approach;

2. The Silent Learner;

3. Individualistic and cooperative learning situations;

4. Challenge and curiosity;

5. Feedback;

6. Direct Method.

The questionnaire was composed of 72 statements, with a rating scale from one to five. Students answered the questions as they applied to their study of English on a 5-point scale, Likert scale. SPSS was used to perform the analysis. A Pearson correlation matrix and the descriptive characteristics of the sample group on students were used.

\section{Data Presentation and Analysis}

The Research Question 1 aimed to define motivational components of foreign language learning among IUS students. In order to define the components, we applied the descriptive characteristics of the sample group on students. We found out that the most preferred motivational factors for IUS students is Extrinsic motivation $(M=34.15)$ and the least is personal Psychological needs $(\mathrm{M}=9.06)$. Table 1 below clearly indicates the preferred motivational components: 
Table 1 Motivational Components of Foreign Language Learning

\begin{tabular}{|l|c|}
\hline Motivational Components & Mean \\
\hline Extrinsic motivation & $\mathbf{3 4 . 1 5}$ \\
Expectations & 26.4 \\
Anxiety & 18.76 \\
Motivational strength & 13.00 \\
Intrinsic motivation & 12.97 \\
Stereotypical attitudes toward Americans \& British & 12.15 \\
Personal psychological needs & $\mathbf{9 . 0 6}$ \\
\hline
\end{tabular}

The students at IUS stated that extrinsic motivation is essential for their second language learning because: English broaden their view, their parents want them to succeed, they want to show off, English will improve their social status, s/he wants to complete studies in English-speaking country, travel abroad, meet new foreign friends, become more educated, read books in English, pass examinations, get better job, have a marvelous life. This implies that the students at IUS are motivated by external factors, factors around them, from the close environment. It is also significant that the IUS students showed least preference towards personal and psychological needs while learning L2. Personal and psychological needs include learning English in order to learn it more than s/he did it in the past, be better than his/her classmates, have good relationship with a teacher, get well on with classmates.

The Research Question 2 aimed to identify preferred learning components/ methods among IUS students. We found out the most preferred classroom practices and activities for IUS students are Balanced approach $(\mathrm{M}=13.15)$, and the least preferred is Direct Method $(\mathrm{M}=4.48)$. Below is the list of the preferred components of IUS learner preferences for specific classroom practices and activities:

Table 2 Preferred Learning Components/Methods

\begin{tabular}{|l|c|}
\hline Preferred Learning Components & Mean \\
\hline Balanced approach & $\mathbf{1 3 . 1 5}$ \\
The Silent Learner & 11.79 \\
Individualistic and cooperative learning situations & 8.52 \\
Challenge and curiosity & 7.36 \\
Feedback & 4.58 \\
Direct Method & $\mathbf{4 . 4 8}$ \\
\hline
\end{tabular}

According to Table 2 the students prefer Balanced approach in the L2 classrooms. Balanced approach stands for the teacher who maintains discipline during the class, students telling their teachers the reasons why they are studying English to be more relevant to their studies, students asking questions when there are not able to cope with the lectures, improving language competences and skills. The least preferred is Direct method which is related to the teacher-centered approach. It is also well known that this method is being replaced by student-centered approach.

The Research Question 3 aimed to identify significant correlation between motivational components and preferred learning components/methods. 


\begin{tabular}{|c|c|c|}
\hline & $\begin{array}{c}\text { Preferred Learning } \\
\text { Components }\end{array}$ & Motivational Components \\
\hline $\begin{array}{ll}\text { Preferred } & \text { Pearson Correlation } \\
\text { Learning Com- } & \text { Sig. (2-tailed) } \\
\text { ponents } & N\end{array}$ & 219 & $\begin{array}{l}-, 146^{*} \\
, 031 \\
217\end{array}$ \\
\hline
\end{tabular}

*. Correlation is significant at the 0.05 level (2-tailed).

We obtained the significant correlation between the Motivational Components and Preferred Learning components. This implies that the students who preferred Balanced approach, The Silent Learner Individualistic and cooperative learning situations, Challenge and curiosity Feedback and Direct Method while learning are motivated by Extrinsic motivation, Expectations, Anxiety, Motivational strength, Intrinsic motivation, Stereotypical attitudes toward Americans \& British and Personal psychological needs.

Table 4 Significant Correlation between Motivational Components and Preferred Learning Components

\begin{tabular}{|l|l|}
\hline Preferred Learning Components & Motivational Components \\
\hline The silent learner & $\begin{array}{l}\text { Anxiety, Intrinsic motivation, } \\
\text { Personal psychological needs }\end{array}$ \\
\hline $\begin{array}{l}\text { Individualistic and cooperative } \\
\text { learning situation approach }\end{array}$ & Anxiety \\
\hline Challenges and curiosity & Motivational strength \\
\hline Balanced approach & $\begin{array}{l}\text { Personal psychological needs, } \\
\text { Motivational strength, Expectations }\end{array}$ \\
\hline
\end{tabular}

Significant correlation between Preferred Learning Components and Motivational Components is presented in the Table 4.

According to the data collected in this research, the students who preferred The silent learner approach are motivated by anxiety, psychological and personal needs and intrinsic triggers. The silent learners, in our case, prefer a teacher to do most of talking and participate in the class just in case they are called upon. What's more, they think that communication activities are a waste of time in the class, and they need to be exposed to the activities which will directly help them pass the examinations. Those students will sit and listen, and mind if they are forced to speak in English. Worry and negative emotional reaction aroused while learning or using a second language is recognized among students who are triggered by anxiety. Those students do not feel comfortable if they have to speak in English, hesitate to volunteer answers in the class, care about teachers' opinion and attitude towards them, and they are afraid of failure at exams. For this reason, their behavior in class actually makes them The Silent learner. Intrinsically motivated students are usually motivated in activities due to their own sake. Variables that affect learner's intrinsic motivation are defined as interest, enjoyment, feeling competence, affiliation toward the target language and a learner's wish to learn L2. It has also been defined as motivation from 'within'. Thus, we can say that intrinsically motivated students prefer to be The silent learner.

The research also showed that students, who are anxious about learning L2, prefer Individualistic and cooperative learning situation approach. For this type of students, the challenge of a task can be high, whereas in most cases the performance is low. Therefore, 
these students prefer to be involved in the class activity individually or in pairs, groups, rather than teacher-centered activities.

Creating activities which are challenging for the curious students who prefer activities and materials that really challenge them so they learn more, activities that allow students participate actively are meant for the students with motivational strength. Those are students, who will enroll and attend the course under any circumstances, study in English for as long as possible, take another English course after completing the current one, work on the strategy to improve his/her English, put best effort into trying to learn English.

The research also showed that the students who are motivated by Personal and psychological need, Motivational strength, and Expectations, are more likely to favor the Balanced method. Balanced approach considers a teacher as a model and facilitators in the class, teaching styles and learning styles are met, the aims and the goals of the course are clear and relevant to students' goals, all skills are improved, the course is much tailored rather than curriculum based. We can say that the majority of students prefer balanced method for learning a second language. In another words, the students struggle to learn more English than they have done in the past, perform much better than others, have good relationship with a teacher and classmates; the students who enroll an attend the course under any circumstances, study in English for as long as possible, take another English course after completing the current one, work on the strategy to improve his/her English, put best effort into trying to learn English. What's more, students that are extrinsically motivated in a way they believe that learning L2 will broaden their views, have expectations from the social environment, show off, improve social status, study in an English-speaking country, and broaden general knowledge using sources in English. Balanced method is observed as a learner-centered approach rather than teacher fronted classroom method. The traditional method focuses on the idea of frontal teaching. Teaching program was aimed to transfer information from teacher to students. Exchanging information between teachers and students has consisted of short questions and answers. Motivation in this form of teaching seems to be unnecessary. Classes which inspire students, make them feel curious, creative and encouraged to think individually, trained for emotional intelligence and social skills (communication, self-control, self-evaluation, etc.), may at the same time provide encouragement and atmosphere for demonstration of student's personality, have an opportunity to change educational way and prepare students for life. Instructors should "involve learners throughout the entire instructional process. Involving the students in deciding on the class direction is likely to create the kind of classroom atmosphere that promote optimal learning" (J. K. Richards and W. A. Renanadya, 2002, p. 362).

\section{Conclusion and Recommendations}

The approach recommended in this paper is designed to meet the goal of successful language learning. The prospect of tailoring language instruction that accommodate different learning styles might appear very difficult for the language instructors. Teaching styles are made up of the methods and approaches with which instructors feel most comfortable, most probably thought in the similar manner throughout their education. When instructors are forced to change their instructional methods, they would also find themselves in an unfamiliar environment and method. This might end up with disastrous results. Fortunately, instructors who wish to address a wide variety of learning styles need 
not make drastic changes in their instructional approach.

While learning a second language, the challenge seems to be the primary determinants of motivation. The challenge and stimuli can trigger an individual and make the process of learning more productive. Many experts agreed that challenge is considered as a form of intrinsic motivation. Besides Direct method, Feedback was not recognized as a preferred learning approach, and was not triggered significantly by the Motivational Components. Feedback with error corrections specify errors and mistakes students make. In order not to discourage students, teachers tend not to correct their students. It is observed that feedback needs to be provided only if it will be beneficial for students. In another words, if feedback can signal improvement, then it is motivating.

In this particular research, 70 students from IUS participated and responded to the questionnaire. The research findings indicated that extrinsic motivation $(\mathrm{M}=34.15)$, was the highest motivational factor for the students. Expectation as a motivational factor $(\mathrm{M}=$ 26.4), was at the second place for the students. Motivational strength with the $M=13.00$ followed as the next motivational factor. Intrinsic motivation $(M=12.97)$, stereotypical attitudes toward Americans \& British $(\mathrm{M}=12.15)$, personal psychological needs (M $=9.06$ ) with their means as shown in the brackets were the least influential factors in students motivation. The results indicate that students are greatly motivated by external factors to learn the language. When it comes to learners preferences for specific classroom practices and activities IUS students showed preference for Balanced Approach $(\mathrm{M}=$ 13.15), and the least preferred method was Direct Method $(M=4.48)$. The correlation between the Motivational Components and the Preferred Learning components was significant. We believe this study will contribute to the academic community, academic staff at International University of Sarajevo and the students.

\section{References}

Al-Hazemi, H (2000) Lexical attrition of some Arabic speakers of English as a foreign language: A study of word loss. TESL Journal. http://www.aitech.ac.jp/ iteslj/Articles/Al-Hazemi-Attrition/learning. Language Learning 38, pp. 75-100

Brown, H. D. (1987). Principles of language learning and teaching. New Jersey: Prentice Hall.

Brown, H.D. (1994). Teaching by Principles. New Jersey: Prentice Hall.

Cook, V. (2000). Linguistics and second language acquisition. Beijing: Foreign Language Teaching and Research Press and Macmillan Publishers Ltd.

Crookes, G. and Schmidt, R. (1991) Motivation: re-opening the research agenda. Language Learning 41:469512.

Dornyei, Z. (1990) Conceptualizing motivation in foreign language learning.Language Learning 40, pp. 46-78.

Dornyei, Z. (1994). Motivation and Motivating in the Foreign Language Classroom.The Modern Language Journal, 78,3, pp. 273-284.

Dörnyei, Z. (2001a) Teaching and Researching Motivation. Harlow: Longman.

Dörnyei, Z. (2001b) Motivational Strategies in the Language Classroom. Cambridge: Cambridge University Press.

Deci, E. L., \&Ryan, R. M. (2002). Overview of self-determination theory: An organismic dialectical perspective. In R. M. Ryan \& E. L. Deci (Eds.), Handbook of self-determination research. Rochester, N.Y.: The University of Rochester Press.

Engin, A. (2009). Second language learning success and motivation. Social Behavior And Personality, 37(8), 1035-1042.

Gardner and Masgoret (2003). Attitudes, Motivation and second Language Learning: A Meta-Analysis of Studies Conducted by Gardner and Associates, Language Learning. 167-21.

Gardner, R., Lambert, W. (1972). Attitudes and Motivation in Second Language Learning. Rowley, MA: Newbury House.

Gardner, R. C. (2002). Social Psychological Perspective on Second Language Acquisition. In R. Caplan (Ed), 
The Oxford Handbook of Applied Linguistics. 102-199. New York, NY: Oxford University Press.

Gardner, R. (1985). Social Psychology and Second Language Learning: the role of attitudes and motivation. London: Edward Arnold.

Horwitz, E. K. (1990). Attending to the affective domain in the foreign language classroom shifting the instructional focus to the learner. Middlebury, VT: Northeast Conference of foreign languageteachers.

Hewitt, E., \& Stephenson, J. (2011)."Foreign language anxiety and oral exam performance: A replication of Phillips's MLJ study”, in The Modern Language Journal, 96: 170-189.

Keller, J. M. (1983). Situation and Task-Specific Motivation in Foreign Language Learning andTeaching.Joensuu.University of Joensuu.

Moiinvaziri, M. (2009). Motivational Orientation in English Language Learning: A study of Iranian Undergraduate Students, available at: thttp://www.usingenglish.com/articles/moral-orientation-in-english-learning.html

MacIntyre, P. D. (1999). "Language Anxiety: A Review of Literature for Language Teachers”. In D. J. Young (Ed.), Affect in foreign language and second language learning. New York: McGraw Hill Companies.

Maslow, A. H. (1962). Towards a psychology of being. Princeton: D. Van Nostrand Company.

Oller, D. K., \& Smith, B. (1997). The effect of final syllable position on vowel duration in infant babbling. Journal of the Acoustical Society of America, 62, 994-997.

Phillips, E. M. (1992). “The effects of language anxiety on students' oral test performance and attitudes" in The Modern Language Journal, 76: 14-26.

Richards, J. C., and Renadya, W. A (2002). Methodology in Language Teaching: An Anthology of Current Practice (Eds). (422 pp.) Oxford University Press.

Santrock, J.W. (2004). Psychology by Santrock. McGrow-Hill (537 pp.).

Schmidt, R. (2006). Motivation and second language acquisition (Eds), Honolulu: University of Hawai’ Press, pp. 1-19.

Stangor, C., Sechrist, G. B., \& Jost, J. T. (2001). Changing Racial Beliefs by Providing Consensus Information. Personality and Social Psychology Bulletin., 27, 484-494.

Schumann, J. H. (1978). The Pidgination Process: A Model for Second Language Acquisition. Rowley, MA: Newbury House.

Woolfolk, A. (1998). Educational psychology (7th ed.). Boston, MA: Allyn \& Bacon (660 pp.). 